\title{
Heterogeneidad estructural y Socialismo del Buen Vivir
}

\author{
Wolney Roberto Carvalho \\ Universidad Federal de la Integración Latinoamericana (UNILA), \\ Foz do Iguaçu, Brasil. \\ Email: wolney.carvalho@unila.edu.br \\ Félix Pablo Friggeri \\ Universidad Federal de la Integración Latinoamericana (UNILA), \\ Foz do Iguaçu, Brasil. \\ Email: felix.friggeri@unila.edu.br
}

Resumen: En este trabajo partimos del planteo de la heterogeneidad estructural que inspirara Mariátegui y continuara Aníbal Quijano, buscando indagar sobre su potencial constructor de una alteridad político-económica al sistema colonial/capitalista. Realizamos también un análisis del tratamiento del tema en algunos autores como Aníbal Pinto, Ignacio Rangel, Celso Furtado y Florestan Fernandes, buscando profundizar la mirada acerca de las relaciones económicas y sociales sobre la problemática del planteo desarrollista en América Latina. Indagamos especialmente cómo desde la realidad del pretendido “atraso” latinoamericano existe una potencialidad de un Socialismo Indoamericano o del Buen Vivir como una construcción original alternativa y opuesta al capitalismo. Quizás como ningún otro tema, el de la heterogeneidad estructural y sus distintas interpretaciones, expresa lo que consideramos el gran dilema de los gobiernos populares latinoamericanos: Desarrollo y/o Buen Vivir.

Palabras clave: Heterogeneidad estructural, Buen Vivir, Socialismo Indoamericano, Mariátegui.

\section{Structural heterogeneity and Socialism for the Good Living}

\begin{abstract}
In this work we begin with the approach of structural heterogeneity that Mariátegui inspired and was continuiedby AníbalQuijano,seeking to investigate its construction potential of a political - economic otherness to the colonial / capitalist system. We also pursued an analysis on the treatment of this topic in some authors likeAníbal Pinto, Ignacio Rangel, Celso Furtado and FlorestanFernandes, seeking to deepen a point of view on the economic and social relations on thedevelopmentalist analysis in Latin America. We investigatedspeciallyon how from the reality of the claimed Latin-American "backwardness" there exists a potentiality for anIndoamerican Socialism or for the Good Living as an original alternativesetting up,and opposite to capitalism. Probably as no other topic, that of structural heterogeneity and its different interpretations, expresses what we consider to be the great dilemma of the Latin-American governments of the people: Development and / or Good Living.
\end{abstract}

Mariátegui.

Keywords: Structural heterogenety, Good Living, Indoamerican Socialism, 


\section{Heterogeneidade estrutural e Socialismo do Bom Viver}

Resumo: Este artigo parte da proposição da heterogeneidade estrutural que inspirou Mariátegui e continuou Aníbal Quijano, procurando indagar sobre potencial construtor de uma alteridade político-econômica aosistemacolonial/capitalista. Também se realizou uma análise do tratamento do assunto em alguns autores como Aníbal Pinto, Ignacio Rangel, Celso Furtado e Florestan Fernandes, buscando aprofundar o olhar sobre as relações económicas e sociais a respeito dos problemas dos modelos de desenvolvimento na América Latina. Indagamos especialmente como a partir da realidade do alegado “atraso"Latino-americanoexiste uma potencialidade de um Socialismo Indo-americano ou do Bom Viver como uma alternativa original e oposta ao capitalismo. Talvez como nenhum outro problema, a problemática da heterogeneidade estrutural e suas várias interpretações, expressa o que nós consideramos o grande dilema de governos populares da Ámérica Latina: Desenvolvimento e/ou Bom Viver.

Palavras-chave: Heterogeneidade estrutural - Bom Viver - Socialismo Indoamericano - Mariátegui.

\section{Introducción}

Entendemos que, resulta de gran importancia recuperar el tema de la heterogeneidad estructural latinoamericana que tuvo diversos tratamientos en los estudios socio-económicos pero que pocas veces fue visto en su dosis de positividad y en su potencialidad alternativa en América Latina. Y porque uno de los primeros -y de los pocos- en plantear este tema desde una perspectiva positiva fue Mariátegui, nos parece importante re-proponer una problematización original y fecunda que tiene mucho que ofrecer a los latinoamericanos en términos de visión alternativa.

En un admirable texto Aníbal Quijano describe esta realidad presentada y analizada por Mariátegui como una "heterogeneidad histórico-estructural, como un modo históricamente constitutivo de toda existencia social, rompiendo de ese modo con el dualismo radical del cartesianismo, que está en el origen mismo del eurocentrismo, y con las propensiones positivistas al reduccionismo y al evolucionismo" y que supone una "subversión epistémica y teórica original” y que es "el núcleo de lo que hoy se discute sobre colonialidad del poder” (Quijano 2007: CXXVIII-CXXIX).

La mirada mediática y -casi incomprensiblemente también- la académica dan por supuesto una tendencia a concebir a uno de esos "dos mundos”, el considerado “atrasado” y donde siempre estarán ubicados indígenas y campesinos, como un mundo a superar, como un mundo que impide el crecimiento ordenado del otro. Un cielo de modernidad capitalista opera silenciosamente como Deus ex machina de un camino acertado. Esto no es discutido, ni discutible. Es un dogma que se evita promulgar expresamente pero que está fuertemente vigente. Así, nuestras sociedades latinoamericanas estarían compuestos de un segmento de gente que se encamina hacia 
este cielo, composición hecha con el liderazgo de las clases que concentran la riqueza y seguida desde distintas posiciones por buena parte de las clases medias incorporadas a un tipo de vida centrado en el consumo y a la sujeción al ordenamiento establecido empresarial-estatalmente. En este esquema los pobres tienen una sola perspectiva "positiva” válida: ser incluidos. O sea "salir" de la exclusión para ir caminando a la clase media. Pero esto implica, "salir" de la barbarie, "salir" de la exterioridad alternativa. Entrar definitiva y subordinadamente al mundo del Orden y el Progreso. Casi está demás aclarar que este primer planteo simplificado, así hecho, está en orden a presentar el tema. Matices, análisis, ambigüedades del mismo están pendientes, aunque algunos esbozaremos en las páginas que siguen. La paradoja que comenzó a desarrollar el pensamiento mariateguiano, pero que estuvo presente también en muchos escritores, ensayistas y artistas latinoamericanos, es que aquel mundo "atrasado" y estigmatizado aparece hoy como portador de la propuesta más clara que aparece en el horizonte de superación del capitalismo: la del Buen Vivir.

El tema se relaciona con el del "dualismo estructural” y con la problemática general que se planteó desde las Teorías del Desarrollo, que tuvo tratamientos y expresiones distintas (y los sigue teniendo). Elegimos aquí una de las descripciones de este planteo:

La polarización social y económica de los países latinoamericanos ha conducido a algunos observadores a hablar de un "dualismo" y de la existencia de "sociedades duales". En esencia, la tesis de la sociedad dual afirma que existen en los países latinoamericanos dos sociedades diferentes y hasta cierto punto independientes aunque necesariamente ligadas entre sí: la primera sería una sociedad arcaica, tradicional, agraria, estancada y retrógrada; la segunda sería una sociedad moderna, urbana, industrializada, dinámica, progresista y en desarrollo. La "sociedad arcaica” está caracterizada por relaciones personales y familísticas, por instituciones tradicionales tales como el compadrazgo, ciertos tipos de trabajo colectivo, ciertas formas de dominación política personalista y relaciones de clientela. También aparecen en ella las estratificaciones rígidas basadas en los status sociales adscritos (en las que la posición del individuo en la estructura social está determinada desde el nacimiento y existen pocas oportunidades para que la modifique durante su vida); y las normas y valores exaltan -o cuando menos aceptan- el statu quo y las formas tradicionales de vida social heredadas del pasado, y constituyen de esta manera un obstáculo al pensamiento económico "racional”. En cambio la "sociedad moderna" consistiría en ciertos tipos de relaciones sociales que los sociólogos llaman secundarias, determinadas por acciones interpersonales motivadas por finalidades racionales y utilitarias; de instituciones con funciones específicas; y de estratificaciones sociales relativamente flexibles en las que el status es adquirido a través del esfuerzo personal y puede expresarse mediante índices cuantitativos (tales como el nivel de ingresos o de educación) y la función social (como la ocupación). En la llamada 
“sociedad moderna” las normas y valores de la gente tienden a orientarse hacia el cambio, el progreso, la innovación y la racionalidad económica. (Stavenhagen 1970: 174-175).

Esta visión de la estructuración dual de América Latina, que tuvo en sus expresiones artísticas quizás su punto más valioso y que vale la pena recuperar para el análisis profundo y complejo de la pobreza en el continente, en sus análisis socio-económicos sufrió el predominio de una visión evolucionista -tanto en planteos de derecha como de izquierda- signados por una visión del desarrollo que tenía siempre como horizonte alguna variante de desarrollo capitalista. Las mismas posiciones de izquierda absorbieron, en mayor o menor medida, este tipo de planteo aunque generalmente en ellos ese horizonte no tuviera un carácter de objetivo final. Pero en ambos la parte "atrasada” de esta estructura era un elemento a superar al estar cargada de una negatividad absoluta. Esta incapacidad para valorizar los elementos populares originales que formaban parte de esa estructura y su potencialidad alternativa es, a nuestro juicio, producto de una visión colonizada.

\section{La heterogeneidad estructural en el pensamiento vinculado a la CEPAL}

La emergencia destacada y el trabajo de análisis más fuertes sobre el concepto de heterogeneidad estructural en América Latina viene del trabajo cepalino. Por eso, aunque con relativa brevedad, entendemos que cabe una resumida presentación y evaluación del mismo para poder avanzar sobre los imaginarios creados sobre el tema, sobre su historia y sus cambios.

Uno de los principales referentes en este tema es el chileno Aníbal Pinto (1972). Él identifica lo que llama “dualismo” como algo propio de las economías primario-exportadoras. Esta dualidad resulta más marcada cuanto más alto es el grado de especialización para el mercado externo en la economía de los países, se estructura así en “enclaves y resto”. Destaca la importancia de la consolidación de un "estado nacional”: allí donde éste existe y es más independiente hay más posibilidades de crecimiento del "resto". En este dualismo tiene una incidencia importante el grado de significación de las economías "tradicionales” para el conjunto de la sociedad, y la permeabilidad entre ambas, poniendo como ejemplo de esto a los "países incaicos”.

Hay una presencia importante de esta temática en los trabajos del marañense Ignacio Rangel. Establece una distinción entre el dualismo existente en el modo de producción característico de la Europa que comienza la conquista americana y el que se iría forjando en América, en base a que aquel era temporario -sería superado por las revoluciones burguesas inglesa y francesa- y a que su estructuración era inversa a la que sobrevendría en América: su polo interno más “avanzado” que el externo (Rangel 1981: 5). 
Esta distinción daría, en principio, elementos para cuestionar el sucesivismoetapista de ciertas posturas basado en una homogeneización de las etapas a nivel mundial, problema que mostró tanto la derecha como parte de la izquierda.

No obstante, hay que notar expresiones que utiliza que, por un lado, tienen tendencias universalizantes para su análisis de la especificidad brasilera y/o latinoamericana. Como cuando utiliza para el mundo precolombino la categoría de "pre-desenvolvido", o, para el caso brasileño, su mención a un "imenso atraso da populaçãoameríndia". Toma como referencia base los cinco modos de producción de lo que llama el materialismo histórico marxista para la descripción del tipo de dualidad que se da en Brasil. Aunque aclara que su análisis -para el caso de la dualidad brasilera- merece un tratamiento más complejo (Rangel 1981: 5.8.11). Aun así, el universalismo homogeneizante no se aparta de la base de su análisis como cuando sostiene:

En suma, a sociedade dual brasileira, respondendo, como qualquer outra formação, ao crescimento de suas próprias forças produtivas, muda de modo de produção e o faz no mesmo sentido geral no qual muda a sociedade humana, passando a um modo de produção superior, mas tem um modo peculiar de mudar, isto é, o faz em obediência a certas “leis” específicas... (Rangel 1981: 12).

Hablatambién de "nosso feudalismo" pero, para el caso brasileño por lo menos, sostiene que tenía "un conteúdo não feudal” ya que el esquema macro se relacionó con otras instituciones que estaban ligadas a otros tipos de modos de producción a los que califica de "mais primitivos", para concluir que "O Brasil nascia, pois, como uma formacão feudal, que associava, em união dialética, um lado feudal com outro pré-feudal". Entre esas "formaçõessociaispré-feudais" están la comunidad primitiva (indios y quilombos negros) hasta la esclavitud (Rangel 1981: 7-8).

En Celso Furtado las economías subdesarrolladas tienen estructura ocupacional con oferta ilimitada de mano de obra y el progreso técnico de elevado coeficiente de capital lo cual no se presta para absorber los trabajadores que vienen de la "economía de subsistencia". La consecuencia de esto es que se tiende a la concentración del ingreso y a un grado creciente de injusticia social. Quedan así relacionados subdesarrollo con heterogeneidad, ya que para él el subdesarrollo es una de las líneas históricas de proyección del capitalismo industrial céntrico que se materializa en empresas capitalistas modernas sobre estructuras arcaicas, esto forma economías híbridas, profundamente heterogéneas.Relaciona también, la heterogeneidad con la estructuración colonial. Por un lado ella da dos grupos de clase dirigente distintos pero no necesariamente antagónicos. La lucha entre conservadores y liberales traduce esta dicotomía de la clase dirigente.Para el análisis de la complejidad de esta realidad, el autor sostiene la necesidad de un análisis histórico-estructural que analice no solo la inserción internacional sino también las características de la realidad social y política de Latinoamérica. 
Un elemento clave para este autor es que en la periferia los negocios fueron administrados, en gran medida, desde afuera, y con vasta implantación de sucursales productivas, comerciales y financieras en los sectores claves en el marco de la división internacional del trabajo. Además, los procesos de industrialización o modernización fueron acompañados por la emergencia de una burguesía periférica identificada cultural e ideológicamente con el centro, la cual fue la responsable por los arreglos políticos para la implantación de la modernización. Pero esta burguesía solo ocupó un lugar secundario en las actividades productivas especialmente en aquellas donde los intereses de los grandes grupos internacionales no se hicieron presentes. Todos los impulsos económicos y dinámicos se originaran desde afuera, sobre todo porque aunque el desarrollo de las fuerzas productivas en el núcleo industrial posibilitó un aumento en la demanda por mercancías producidas en la periferia, acompañada de reflejos en la productividad, ese aumento se dio con base en la especialización exigida por la división internacional del trabajo, la cual a su vez, no permitió la formación de una demanda interna que estimule el surgimiento de otros sectores económicos y el desarrollo propio de las fuerzas productivas. Si en el núcleo central el desarrollo capitalista se presenta como producto y presupuesto del desarrollo de las fuerzas productivas, en la medida que avanza la industrialización y se diversifica la demanda - a su vez estimulada tanto por el consumo de los capitalistas como por el consumo de los trabajadores - en la periferia, dada su fuerte vocación agrario-exportadora orientada desde y hacia afuera, tanto la demanda capitalista como la demanda de los trabajadores son débiles, lo que acaba por reflejarse en un bajo grado de desarrollo económico. Por tanto,

O que veio a chamar-se de subdesenvolvimento não é outra coisa senão a manifestação dessa disparidade entre o dinamismo da demanda e o atraso na acumulação reprodutiva. Este tem sua origem na forma de inserção no sistema de divisão internacional do trabalho e o primeiro na penetração dos padrões de consumo do centro. (Furtado 1981, 90)

Así, remarca una diferencia entre centro y periferia que hace a la estructuración heterogénea de esta misma:

Mientras que en las economías centrales la acumulación condujo a la escasez de fuerza de trabajo, lo cual creó las condiciones para que surgiesen presiones sociales que favorecerían la elevación de los salarios reales y la homogeneización social, en las periféricas los efectos fueron por completo distintos: dio lugar a la marginalización social y reforzó las estructuras tradicionales de dominación, o las sustituyó por otras similares. En la realidad, la acumulación periférica estuvo al servicio de la internacionalización de los mercados que trajo consigo la difusión de la civilización industrial. (Furtado 2001, 58)

Además, hay que resaltar que en términos del comercio exterior el sector dinámico continúa siendo el primario-exportador, y será a través de 
este sector que parte de los equipamientos y tecnología requeridos para la industrialización sustitutiva podrán ser importados. Este tipo de industrialización, a medida que agrega mayor participación de las transnacionales, exige una fuerte concentración de los ingresos, por un lado para los financiamientos que requiere, $y$, por otro, como forma de incrementar una demanda modernizadora de las capas dominantes en la periferia (Furtado 1981). Así, esas grandes empresas internacionales empiezan gradualmente a orientar parte de la producción al mercado mundial con gran capacidad competitiva, eso es resultado de la disponibilidad de una gran oferta de fuerza de trabajo y a bajo costo - en general libre de la orientación sindical verificada en el centro - e incluso del fácil acceso a las fuentes de materias primas. En las décadas posteriores, a pesar de un período de fuerte crecimiento económico por el que pasaron las economías más importantes de Latinoamérica en la década de 70, como Brasil, Argentina e México, aumentó el papel y la actuación de las empresas transnacionales y el mercado interno fue poco estimulado para generar un desarrollo autónomo de estas economías.

Por tanto, se entiende que, para Furtado, la formulación del desarrollo autónomo pasa por un pacto con la burguesía nacional, la cual deberá maximizar la potencialidad creativa y tecnológica buscando transformar el parque productivo latinoamericano, acompañado de una fuerte participación estatal en cuanto al establecimiento de un sistema de crédito eficiente, la creación de la infraestructura básica y la implantación de empresas públicas en sectores estratégicos y de baja rentabilidad en el corto plazo.

\section{El subdesarrollo como un producto del capitalismo dependiente}

Para FlorestanFernandes (1972), las raíces del subdesarrollo pueden ser identificadas cuando se analizan las formas de dominación externa que se implantaron desde los principios de la colonización. La primera forma de dominación externa fue la dominación colonial, que estuvo a cargo de Portugal e España. Mediante el trasplante de los padrones ibéricos de estructura social, se estableció un sistema de poder, control y apropiación de las riquezas de la colonia latinoamericana que preservaban la dominación de los colonizadores y el status de la corona para decidir qué producir, cómo producir y para qué/quién producir. Entonces, desde finales del siglo XV hasta el siglo XVIII, se implantó una explotación ilimitada de los recursos latinoamericanos que se quedaron en "tesis" en España y Portugal. El segundo tipo de dominación externa se procesó desde el final del siglo XVIII hasta la primera mitad del siglo XIX, período de desagregación del antiguo sistema colonial. Las naciones europeas, sobre todo Inglaterra, dominaron los negocios de exportaciones e importaciones. Las insurgentes élites latinoamericanas, al continuar operando en la antigua estructura colonial, ahora exportando materias-primas requeridas por el mercado mundial capitalista, eligieron con eso un papel secundario y dependiente en los marcos del 
desarrollo del capitalismo mundial. El tercer tipo de dominación externa fue característico de la reorganización del sistema colonial de acuerdo con las necesidades de expansión del mercado capitalista mundial en su fase imperialista. Todas las naciones europeas y Estados Unidos tuvieron alguna influencia en las últimas cuatro décadas del siglo XIX, aunque Inglaterra fue la que más se benefició por actuar tanto en sectores de infraestructura como transporte, electricidad, como en el sector inmobiliario, comercial/ financiero y productivo. Se establecen las bases del capitalismo dependiente en Latinoamérica y con ello las del subdesarrollo.

Según Fernandes (2008), una sociedad subdesarrollada posee un orden económico capitalista y reproduce las condiciones de existencia y funcionamiento del régimen social de este orden. Pero también, su estructura histórica muestra una autonomía limitada en términos de la reproducción específicamente capitalista, y eso porque surgió en el marco del capitalismo mundial como una entidad especializada, subsidiaria y dependiente de las aplicaciones reproductivas del excedente social desde el siglo XVI. En cuanto las economías desarrolladas implantaban las bases específicas de la reproducción capitalista basándose en la acumulación originaria dada en Europa y en el pillaje de las colonias americanas, las economías periféricas y dependientes jamás lograron lomismo por su fuerte dependencia económica de los países centrales. Además, los ciudadanos de los respectivos Estados latinoamericanos no consiguieron, a lo largo del siglo que antecede la industrialización de los años 30, acumular la suma de capitales requerida para la implantación de un capitalismo autónomo. Por tanto:

Na verdade, a transição inicial se fez, nos países subdesenvolvidos, sob o impulso da inclusão no mercado mundial, a qual envolveu extensa e contínua transferência de capitais, técnicas e instituições econômicas, agentes humanos treinados das nações europeias, que controlavam aquele mercado, para as nações emergentes ou para as colônias. Além disso, o aproveitamento das riquezas previamente acumuladas, absorvidas quase sempre por grandes proprietários rurais ou grandes negociantes, geralmente não coincidiu nem nunca levou a algo similar às revoluções agrícola e comercial de estilo europeu. No setor agrícola, a extinção do sistema colonial não provocou o colapso das antigas estruturas econômicas coloniais; ao contrário, as exigências do mercado mundial e da comercialização das matérias-primas em larga escala exigem sua persistência, como garantia ao aumento contínuo da oferta e dos grandes lucros dos importadores europeus. (Fernandes 2008: 44)

En esta dirección, aun cuando se destinó para el mercado interno parte de las ganancias del sector vinculado al comercio exterior - exportaciones e importaciones, de los bancos y otros servicios - en suelo latinoamericano pero operados desde afuera, el proceso de industrialización surgió incentivado, orientado y manteniendo lazos intensos con las metrópolis desarrolladas. Eso fue reflejo de la enorme participación y control del crecimiento interno de las economías periféricas por parte de los grandes 
grupos empresariales de los países desarrollados. A través de notables sumas de capitales y de tecnologías traídas desde el centro e invertidas en América Latina, los principales sectores del mercado interno se estructuraron y empezaron por atender la demanda de la clase capitalista por bienes de consumo y la de una pequeña parcela de la población que se incorporaba a través de la venta de la fuerza de trabajo. Se destacan por tanto tres aspectos importantes: el primero es que la reproducción capitalista pasó a operar volcada hacia un mercado interno muy débil, pues el consumo capitalista no estaba articulado a través de sus diversos estadios como la producción de bienes de capital, bienes de consumo durables y bienes de consumo de los trabajadores, y eso refleja una demanda capitalista débil por parte de esos sectores; el segundo es que la demanda de equipamientos y tecnología necesarios para la producción de los bienes de consumo demandados por los capitalistas y los trabajadores asalariados, son importados; el tercero es que el mercado interno se constituía orientado desde afuera, y el sector primario-exportador continuó siendo importante fuente de materias primas para el mercado mundial, de ahí que la industrialización latinoamericana después de la independencia prosperó vinculada a una demanda interna y modernizada que requería una pequeña parcela de trabajadores asalariados. Estos últimos coexisten al lado de otras formas de trabajo extracapitalistas (de "subsistencia”, esclavo o semiasalariado). Para los que venden su fuerza de trabajo regularmente, la inexistencia de sindicatos para la defensa de las reivindicaciones de clase acababa por conducir a la superexplotación, siendo esa una forma de aumentar la competitividad de los sectores vinculados al mercado internacional transfiriendo parte del trabajo excedente, de la plusvalía.

De todas maneras, hay que subrayar que los intereses del homo economicus latinoamericano solo prevalecieron donde y cuando no se chocaban con los intereses del capital y del mercado mundial. Incluso los Estados y sus economías nacionales dependientes estuvieron a cargo de Estados con poder global y hegemónico en el mercado mundial.

Assim, à medida que o crescimento dessas economias se encaminha no sentido da autonomização, os mecanismos de controle são reorganizados em torno da produção e do consumo internos. As grandes firmas e organizações das economias nacionais avançadas disputam entre si as oportunidades de alocação econômica no mundo subdesenvolvido, intensificando a redução das economias nacionais dependentes, dotadas de melhores perspectivas de autonomização em bases capitalistas, em verdadeiras economias de consumo. Isso põe fim ao mito segundo o qual a autonomização do desenvolvimento econômico capitalista seja uma função da capacidade revelada pelas economias capitalistas dependentes de absorver os modelos econômicos das nações hegemônicas. (Fernandes 2008: 46)

No se constituyeron, entonces, mercados integrados en escala regional y nacional capaces de estimular el desarrollo de un capitalismo autó- 
nomo y fuerte, especialmente porque los sectores más dinámicos fueron absorbidos por las grandes empresas o empresas asociadas -de capital nacional y extranjero- y porque las mismas concentraron la adopción de la modernización en cuanto a la introducción tecnológica y a la producción de mercancías y servicios. Los sectores “arcaicos” a su vez, donde la producción en general no era basada en los presupuestos de la modernización capitalista, se convirtieron en espacios de transferencia de excedente económico para los centros modernizados. Entonces, el período que abarca las dos guerras mundiales e incluye la depresión de los años treinta puede ser caracterizado como una fase en que empezaron los procesos de industrialización y en la que ya ocurre el predominio de las grandes empresas -algunas de capital asociado- en los sectores más importantes y dinámicos (Fernandes 2008). Después de 1945 la configuración del capitalismo latinoamericano fue marcada por el predominio del capital monopolista en los principales sectores económicos. Ese predominio aparece como un producto y presupuesto del capitalismo dependiente en los países de Latinoamérica, en especial porque refleja la fuerte participación de los grandes grupos económicos internacionales en las actividades económicas más importantes en los sectores de servicios, comercialización y en la industria pesada y leve. Estas grandes empresas estadounidenses, europeas y japonesas trajeron a la región nuevos padrones de producción capitalista, comercialización, marketing y competencia. Esto evidencia, nuevamente, que la burguesía de América Latina no consiguió superar el subdesarrollo e implantar las bases de un capitalismo autónomo. Las élites que comandan el poder político, cultural y económico, preocupadas con las ganancias de corto plazo e ilusionadas con que eran modernas como las élites centrales, no se preocuparon en construir una verdadera revolución industrial, con poder para superar el subdesarrollo (Fernandes 1972).

En la medida en que avanza el capital monopolista en los Estados nacionales de América Latina, su burguesía profundiza los lazos de dependencia y subyuga todavía más las estrategias del desarrollo al de la economía mundial capitalista. Además, con los intentos de integración y desarrollo regional, en los marcos de la constitución de un bloque económico, las burguesías latinoamericanas de los principales países -en especial Brasil y Argentina- intentan ahora la imitación de los sucesos imperialistas del siglo XIX en el marco de Mercosur, Unasur y CELAC, como Alemania, Francia, Italia y Japón imitaron a Inglaterra en el final del siglo XIX en el marco del mercado mundial.

El pensamiento sobre la heterogeneidad estructural que madura en la reflexión cepalina si bien, como vimos, tiene elementos interesantes que plantean caminos investigativos fecundos, tiene una doble dificultad. Por un lado, permanecer -fundamentalmente desde un no desprendimiento de la matriz evolucionista del pensamiento eurocéntrico- atada a una visión básicamente negativa de esa otra parte de Latinoamérica que no es claramente capitalista. Por otro, y en la misma línea básica, haber concretado un pensamiento complejo sobre América Latina, pero con dificultades fundamentales también de base epistémica- para ser un pensamiento desde América Latina. 


\section{Aníbal Quijano y la recuperación del tema desde Mariátegui}

En la búsqueda de un pensamiento que valore esa otra parte no capitalista y protagonizada por los más pobres del continente -que coincide con sus habitantes originarios y con los que fueron reducidos a una situación socioeconómica similar, como en el caso de los afroamericanos y de las mayorías campesinas- Aníbal Quijano realiza el hallazgo de retomar uno de los pensamientos más profundos en este sentido: la obra de José Carlos Mariátegui. Desde allí repiensa la categoría de heterogeneidad estructural abriendo las puertas a una mirada que valoriza el potencial revolucionario que tiene esa otra parte no capitalista del mundo latinoamericano. La perspectiva mariateguiana de la heterogeneidad cultural nos permite mirar también el fenómeno que ha sido llamado como "pobreza estructural” desde la riqueza de un análisis histórico-cultural y socio-económico que nos aporta otros contenidos en cuanto a las causas y consecuencias del fenómeno.

Nos pone también en sintonía con la búsqueda de caminos de superación del capitalismo que no necesariamente pasan por su "maduración" sino que arrancan de otras racionalidades y otras estructuraciones socioeconómicas ajenas a él. El análisis y la acentuación de las potencialidades de estas formaciones "Otras" es una deuda del pensamiento latinoamericano, aunque han venido trabajando en ellas autores como García Linera (2008).

La conformación latinoamericana de la heterogeneidad estructural bajo la égida capitalista y, sobre todo, la pobreza estructural que en ella subsiste desde la conquista, no es sino, fundamentalmente, la contracara del capitalismo. Posibilitó la existencia del capitalismo mundial a través de los procesos de acumulación que lo posibilitaron y fortalecieron. Capitalismo y pobreza estructural latinoamericana son dos caras de la misma moneda.

Quijano llega a este punto, en una etapa de crítica al pensamiento cepalino, que lo ubica cerca de la Teoría de la Dependencia y dentro del planteo de la Teoría del Colonialismo Interno. Desde allí va forjando herramientas conceptuales desde donde poder distanciarse de la sujeción al pensamiento eurocéntrico y llega a los planteos de Colonialidad del Poder y de Racismo de Clase que lo habilitan para analizar desde una base epistemológica alternativa la realidad socioeconómica latinoamericana y para pensar el camino revolucionario en América Latina como camino propio, "ni calco, ni copia” al decir de su maestro. Así, caracteriza al capitalismo como: "un patrón de dominación/explotación/conflicto, articulado en torno del eje capital-trabajo mercantilizado, pero que integra todas las otras formas históricamente conocidas de trabajo...”, dejando replanteado aquí el tema de la heterogeneidad estructural en América Latina. Desde su planteo de la Colonialidad del Poder, reubica los términos de la construcción científica y de la consiguiente, lucha política, allí integra lo racial con la estructura de clases en el patrón de dominación. Asocia la desigualdad a la produc- 
ción cultural y especialmente la intelectual. El concepto de "Raza”, como instrumento universal de clasificación social y eficaz mecanismo de dominación por profundización de la naturalización de las relaciones económico-sociales, es constitutivo de la "modernidad".

Y siguiendo a Quijano (2012), en una mirada a las más recientes etapas del capitalismo en nuestra región, se puede sostener que la revolución técnico científica llevada a cabo por el capital después de la Segunda Guerra, condujo a la aparición de un desempleo estructural por la prescindibilidad de parte de la fuerza de trabajo. Se desarrolló un proceso de financierización estructural en escala mundial; se consolidó un socialismo burocrático y en expansión, con fuerte influencia de la colonialidad del poder, tan represivo como la propuesta moderna eurocéntrica. Luego de 1973, los movimientos del capital industrial/financiero mundialmente concentrado, disfrutando del poder global, imponen para América Latina la "financierización estructural" y la "desocupación desestructural", así como para los otros países en mayor o menor escala. Eso provocó la destrucción de las organizaciones de trabajadores, a lo que se suma la desarticulación de los estados socialistas, con excepción de China que rearticuló su burocracia y la puso en alianza con el capital industrial/financiero global. basada en:

Por tanto, en la actualidad está actuante una reconfiguración global

1) la reprivatización de los espacios públicos, del Estado en primer término; 2) la reconcentración del control del trabajo, de los recursos de producción y de la producción/distribución; 3) la polarización social extrema y creciente de la población mundial; 4) la exacerbación de la "explotación de la naturaleza"; 5) la hiperfetichización del mercado, más que de la mercancía; 6) la manipulación y control de los recursos tecnológicos de comunicación y de transporte para la imposición global de la tecnocratización/instrumentalización de la colonialidad/modernidad; 7) la mercantilización de la subjetividad y de la experiencia de vida de los individuos, principalmente de las mujeres; 8) la exacerbación universal de la dispersión individualista de las personas y de la conducta egoísta travestida de libertad individual, lo que en la práctica equivale a la universalización del "sueño americano" pervertido en la pesadilla de brutal persecución individual de riqueza y de poder contra los demás; 9) la "fundamentalización" de las ideologías religiosas y de sus correspondientes éticas sociales, lo que re-legitima el control de los principales ámbitos de la existencia social; 10) el uso creciente de las llamadas "industrias culturales” (sobre todo de imágenes, cine, tv, video, etc.) para la producción industrial de un imaginario de terror y de mistificación de la experiencia, de modo de legitimar la "fundamentalización” de las ideologías y la violencia represiva (Quijano 2012, 51)

El Buen Vivir, como forma de resistencia frente a un nuevo patrón de los conflictos que busca defender la supervivencia de la especie humana, y 
además de la propia tierra frente al desarrollo de ese capital industrial/financiero que por la búsqueda de ganancias no tiene límites, abre espacio para que la población mundial desintegre la colonialidad del poder global y del capitalismo. Por eso, se entiende que las discusiones y contribuciones acerca del Buen Vivir no han buscado acabar con la heterogeneidad/históricoestructural de América Latina, sino reconocer que ella es un producto histórico social mundial, a partir del cual es posible romper y construir una sociedad liberada de la dominación, de la explotación del capitalismo global con una mirada a la experiencia histórica.

Se ha debatido mucho acerca del futuro, incluso sobre las posibilidades de superación del subdesarrollo económico. Se entiende que lo más importante de todo, es tener en cuenta que el subdesarrollo económico es un producto histórico del desarrollo mismo del capitalismo en escala mundial, como se demostró en Furtado y Fernandes, a pesar de los diferentes enfoques y alternativas sobre el tema. En segundo lugar, la superación del primero pasa por reconocer que hay que buscar alternativas que rompan la lógica de poder y explotación que subyace al subdesarrollo, como algunas de las propuestas del Buen Vivir:

a) la igualdad social de individuos heterogéneos y diversos, contra la desigualizante clasificación e identificación racial/sexual/social de la población mundial; b) por consiguiente, las diferencias, ni las identidades, no serían más la fuente o el argumento de la desigualdad social de los individuos; c) las agrupaciones, pertenencias y/o identidades serían el producto de las decisiones libres y autónomas de individuos libres y autónomos; d) la reciprocidad entre grupos y/o individuos socialmente iguales, en la organización del trabajo y en la distribución de los productos; e) la redistribución igualitaria de los recursos y productos, tangibles e intangibles, del mundo, entre la población mundial; f) la tendencia de asociación comunal de la población mundial, en escala local, regional, o globalmente, como el modo de producción y gestión directas de la autoridad colectiva y, en ese preciso sentido, como el más eficaz mecanismo de distribución y redistribución de derechos, obligaciones, responsabilidades, recursos, productos, entre los grupos y sus individuos, en cada ámbito de la existencia social, sexo, trabajo, subjetividad, autoridad colectiva y corresponsabilidad en las relaciones con los demás seres vivos y otras entidades del planeta o del universo entero. (Quijano 2012, 53)

Junto a esto, una referencia a un tema poco incorporado en los análisis: el desarrollo de las fuerzas productivas, que no necesariamente es una amenaza a la humanidad, en especial porque, además de ser estimulado por el poder y por el capital para la producción del lucro, es producto del trabajo humano, y podrá ser utilizado para la producción de la vida, como por ejemplo, libertando gradualmente a esos hombres de su absorción en el trabajo cotidiano, abriendo espacios para el desarrollo de otras potencialidades; aumentar y mejorar la producción de alimentos, viviendas, transpor- 
te colectivo y medicamentos con menor tiempo de trabajo social; incluso monitorear la naturaleza y recuperarla rescatando el concepto de la Pachamama.

\section{Socialismo Indoamericano y Socialismo del Buen Vivir}

Aquí cabe también una recuperación del concepto de Socialismo Indoamericano de Mariátegui y una de las expresiones que enriquece este concepto es la de Socialismo del Buen Vivir, expresión que puede acercarse a una búsqueda latinoamericana de valorización del potencial de aquel mundo considerado como "atrasado" en discursos de derecha e izquierda para proponer una alternativa al predominio omnímodo del capitalismo. Para proponer un horizonte post-capitalista enraizado en la vida y en la praxis de nuestros pueblos. Al utilizarlo nos distanciamos de su utilización en algunos sectores -como la que se realiza desde el gobierno ecuatoriano cuyas ambigüedades hacen difícil una identificación con él (Lalander - Ospina P. 2012). Al trabajar con este concepto queremos situarnos en la línea mariateguiana del Socialismo Indoamericano, como búsqueda, como "creación heroica” que busca sus raíces en lo más profundo de lo latinoamericano que es lo indígena. Y hoy el Buen Vivir aparece como una de las expresiones más claras que condensa ese contenido "indoamericano" por eso nos parece feliz el término aunque es vital trabajar el contenido del concepto, y sobre todo desde los planteos del Movimiento Indígena. Al re-proponer el concepto de Socialismo del Buen Vivir nos colocamos en la línea de Macas (2010) que sostiene que el Buen Vivir no es solo una propuesta de indígenas para indígenas.

Para dimensionar por lo menos algunos elementos que reflejan la importancia de esta propuesta incluyendo sus potencialidades y sus dificultades, realizamos a continuación una breve enumeración sin ninguna pretensión de análisis exhaustivo que puede funcionar también como agenda de investigación.

En el análisis de sus potencialidades, encontramos en primer lugar el hecho de tratarse de la propuesta más clara construida desde nuestra región que configura un horizonte post-capitalista y que cuenta con la ventaja de no ser solamente una idea teórica o una utopía lejana, sino de ser algo que tiene siglos de construcción en nuestra región y que, con innumerables heridas, sigue viva en muchísimas comunidades, fundamentalmente indígenas y campesinas.

En un segundo aspecto de sus potencialidades está el de proponer en forma fuertemente resignificada un proyecto que impulsó el enfrentamiento al capitalismo, como ha sido el socialismo. Entre los elementos claves de esta reivindicación están: 1) que implica que la dimensión revolucionaria con que desafía lo económico-político es clarísimamente también una revolución epistémica capaz de liberar de la dependencia de la episteme moderno/occidental/colonial que estuvo presente en los planteos revolu- 
cionarios del socialismo marxista y anarquista; 2) que juntamente a esto implica un enraizamiento profundo de la praxis y de la conciencia revolucionaria frente al capitalismo en América Latina, algo cercano a lo que expresaba Mariátegui cuando quería "hacer hablar a Marx en quechua"; 3) que puede estimular la reflexión sobre aquel planteo del viejo Marx, en sus cartas a Vera Zasulich y al Consejo Editorial de OtechestvennyeZapiski, de un camino al socialismo que no pase necesariamente por el capitalismo, protagonizado por las comunas campesinas, entendido como "la mejor oportunidad que jamás la historia haya ofrecido a un pueblo” (Marx 1990: 172). Este diálogo de saberes entre los movimientos indígenas y campesinos y su reflexión ancestral y el marxismo, entendemos que puede revitalizar el potencial revolucionario del marxismo en América Latina enraizándolo en la vida y la praxis de nuestros pueblos.

En un tercer lugar, está en que este planteo incorpora y busca la concreción radical de buena parte de las aspiraciones que encarnaron el retorno al poder de los gobiernos populares que sucedieron a la "crisis del consenso neoliberal” en América Latina. El mismo Hugo Chávez quizás el personaje emblemático en el impulso del camino de integración latinoamericano y el creador de un modelo contra-hegemónico inspirador que, acertadamente, Cristina Fernández de Kirchner evocara como "el paradigma Chávez”, sostenía como inspiración fundamental de su propuesta de Socialismo del Siglo XXI, junto a elementos históricos de la lucha por la justicia y la integración latinoamericana y a elementos del cristianismo, la inspiración indígena de este proyecto cuando reclamaba por:

Un socialismo nuevo, fresco. Aquí en América Latina creo que el socialismo, como decía Mariátegui, debe tener un fuerte componente indigenista, socialismo indigenista (...) no se trata de copiar modelos, creo que fue uno de los grandes errores del intento socialista del siglo XX (...) Porque nuestros aborígenes, nuestros indígenas, los pueblos originarios han conservado sus raíces socialistas. Y esas raíces socialistas, esas semillas socialistas que se conservaron en muchos espacios de nuestra América cuánto nos van a ser útiles para el impulso del nuevo socialismo, de nuestro socialismo, indoamericano (...) (Chávez F. 2009: 144)

Un cuarto elemento es la gran capacidad abarcativa que tiene la propuesta en todos los órdenes tanto económico, político, epistémico, ecológico, espiritual. Esto dado su origen cosmovisional que evita cualquier tipo de compartimentación del saber y de la praxis.

Un quinto elemento, y esto dado su origen popular, es que su implementación tendría que potenciar la constante referencialidad -hecha participación, consulta, diálogo de saberes- con las mayorías pobres del continente en la gestación y concreción del proyecto. Así la interacción entre los Movimientos Sociales populares -especialmente indígenas y campesinos- y los demás segmentos de representación política podría tener un impulso fecundo. 
Entre las dificultades que presenta, que son muchas como con cualquier proyecto auténticamente revolucionario, están, en primer lugar, su comprensión y puesta en práctica en los sectores más occidentalizados de nuestra sociedad. América Latina tiene importantes procesos de descampesinización y urbanización bajo un imaginario occidentalista que es fuertemente influyente en las ciudades. En este impulso, además de la rémora de una educación que no ha podido superar claramente un imaginario occidentalista, está la acción de los grandes medios de comunicación difusores privilegiados de ese imaginario de la mano de su ligazón al imperialismo cultural y a la promoción de un consumo con inmensas dosis de artificialidad. A esto vale la pena sumar, que los propios gobiernos llamados populares en América Latina, han levantado, en varias ocasiones, como bandera el "pase" a la clase media de grandes sectores considerados bajo la línea de la pobreza. Sin negar los inmensos méritos que constituye el mejorar los ingresos de buena parte de la población, no hay que olvidar que ese "pase" implica también, en muchas ocasiones, una transformación del imaginario identitário. Y "ser de clase media” tiene, para importantes sectores, el peso de la distancia con un pasado ligado a lo indígena o a lo campesino de cualquier manera.

En un segundo lugar, unido a este primer aspecto destacado, está la participación y el nivel de conciencia de los sectores marginales urbanos. Las popularizadas como "masas marginales" fundantes hoy ya tienen su origen rural demasiado lejano, y aunque esto ha sido realimentado por nuevos grupos migrantes, la realidad es mucho más compleja que en las cercanías de la mitad del siglo pasado, cuando con mucha claridad el pobre urbano estaba intrínsecamente ligado a un imaginario campesino y a sus valores. La penetración mediática -verdadero "sistema educativo" de la actualidad- y con muchísima fuerza, la potentísima presencia del narcotráfico en los márgenes urbanos, son dos elementos claves para una parcial desestructuración de redes de solidaridad y de transmisión de valores -con más mediato o remoto origen rural- que complejizan cualquier proyecto de revalorización del Buen Vivir, aún sin inviabilizarlo totalmente.

En un tercer lugar está el enfrentamiento, ya brutal en muchos lugares, y en la medida en que se evidencie su capacidad de concreción es posible que mucho más todavía, con los sectores de poder, especialmente destacaríamos tres: el mediático, el judicial y el empresarial agrario-minerofinanciero. Frente al retroceso, por lo menos parcial, del sector militar y el industrial en nuestros países, la instrumentalización de los intereses de los grandes poderes económicos se concentró más bien en aquellos que hoy muestran mayor capacidad de frenar las movilizaciones populares en la lucha por un sistema más justo y de condicionar fuertemente el accionar político-estatal cuando se solidariza con las mayorías populares. También tienen una mayor capacidad de impulsar la coerción y la violencia sobre estas mayorías evitando un contacto directo con ellas. Apoyan y comandan acciones de opresión y de violencia desde lugares que tienen apariencia de inaccesibilidad y que nublan la evidencia de sus responsabilidades. 


\section{Consideraciones finales}

Queda presentado aquí el desafío de profundizar en estos planteos tratando de recuperar la riqueza y complejidad del análisis latinoamericano sobre su propia condición de heterogeneidad estructural, pero resignificándola profundamente desde la visión del Buen Vivir que abre caminos para retomar la reflexión sobre un socialismo propio, como configuración y estructuración de un camino superador de la sujeción humillante al capitalismo mundial. La profundización teórica de este camino entendemos que podemos -y debemos- realizarla desde fuentes latinoamericanas, principalmente del camino iniciado por Mariátegui y de la reflexión y la praxis que viene produciendo el Movimiento Indígena y los movimientos campesinos por sí mismos fundamentalmente y, también, por otros intelectuales solidarios con ellos. 


\section{Bibliografía}

Chávez Frías, Hugo (2009), 2006 “Año de la Participación y el Poder Popular”. Selección de discursos del Presidente de la República Boliviariana de Venezuela Hugo Chávez Frías. Tomo VIII, Ediciones de la Presidencia de la República, Caracas.

Fernandes, Florestan (1975), Capitalismo dependente e classes sociais na América Latina. 2da. edición, Zahar, Rio de Janeiro.

Ídem (2008), Sociedade de classes e subdesenvolvimento. 5ta. edición revisada, Global, São Paulo.

Furtado, Celso (1981), Pequena introdução ao desenvolvimento: enfoque interdisciplinar, Companhia Editora Nacional, São Paulo.

Ídem (2001), El capitalismo global. Fondo de Cultura Económica, México.

García Linera, Álvaro (2008), La potencia plebeya. Acción colectiva e identidades indígenas, obreras y populares en Bolivia, CLACSO/Prometeo, Buenos Aires.

Lalander, Rickard - Ospina Peralta, Pablo (2012), “Movimiento Indígena y Revolución Ciudadana en Ecuador”, en Cuestiones políticas, vol. 28, n 48, enero-julio, p. 13-50.

Macas, Luis (2010), “El SumakKawsay”, en Yachaykuna, n 13, Quito, ICCI, junio, p. 13-39.

Marx, Karl (1990), “Karl Marx: Carta al Consejo Editorial de OtechestvennyeZapiski”, en Shanin, Teodor (edit.), El Marx tardío y la vía rusa. Marx y la periferia del capitalismo, Revolución, p. 171-174, Madrid.

Pinto, Aníbal (1972), La “heterogeneidad estructural": aspecto fundamental del desarrollo latinoamericano, Curso de Planificación Regional del Desarrollo/Naciones Unidas, Santiago de Chile.

Quijano, Aníbal (2000), “El fantasma del desarrollo en América Latina”, en Revista Venezolana de Economía y Ciencias Sociales, Vol. 6, Nro 2, mayoagosto, p. 73-90.

Ídem (2007), “Treinta años después: otro reencuentro. Notas para otro debate”, en Mariátegui, José Carlos, 7 ensayos de interpretación de la realidad peruana, Fundación Biblioteca Ayacucho, p. CXIII-CXXIX, Caracas.

Ídem (2012), “ 'Bien Vivir': entre el 'desarrollo' y la des/colonialidad del poder”, en Viento Sur, n 122, Mayo, p. 46-56, Madrid. 
Rangel, Ignacio (1981), “A história da dualidade brasileira”, en Revista de Economia Política, Vol. 1, n 4, outubro-dezembro, p. 5-34.

Santos, Boaventura de Sousa (2010), "Hablamos del Socialismo del Buen Vivir", en América Latina en Movimiento, n 452, febrero, p. 4-7.

Stavenhagen, Rodolfo (1970), “Marginalidad, participación y estructura agraria en América Latina”, en Demografía y Economía, IV: 3, p. 267-291.

Recibido: 30.03.2015

Aceptado: 10.04.2015 